Review

\title{
Neutrophils and Platelets: Immune Soldiers Fighting Together in Stroke Pathophysiology
}

\author{
Junaid Ansari ${ }^{1, *}$ and Felicity N. E. Gavins ${ }^{2, *}$ (D) \\ 1 Department of Neurology, Louisiana State University Health Shreveport, Shreveport, LA 71130, USA \\ 2 The Centre for Inflammation Research and Translational Medicine (CIRTM), Department of Life Sciences, \\ Brunel University London, Uxbridge, Middlesex UB8 3PH, UK \\ * Correspondence: junaid.ansari@lsuhs.edu (J.A.); felicity.gavins@brunel.ac.uk (F.N.E.G.); \\ Tel.: +1-318-626-4282 (J.A.); Tel.: +44-(0)1895-267-151 (F.N.E.G.)
}

check for updates

Citation: Ansari, J.; Gavins, F.N.E. Neutrophils and Platelets: Immune Soldiers Fighting Together in Stroke Pathophysiology. Biomedicines 2021, 9 , 1945. https://doi.org/10.3390/ biomedicines 9121945

Academic Editor: Jun Lu

Received: 9 November 2021

Accepted: 14 December 2021

Published: 19 December 2021

Publisher's Note: MDPI stays neutral with regard to jurisdictional claims in published maps and institutional affiliations.

Copyright: (c) 2021 by the authors. Licensee MDPI, Basel, Switzerland. This article is an open access article distributed under the terms and conditions of the Creative Commons Attribution (CC BY) license (https:// creativecommons.org/licenses/by/ $4.0 /)$.

\begin{abstract}
Neutrophils and platelets exhibit a diverse repertoire of functions in thromboinflammatory conditions such as stroke. Most cerebral ischemic events result from longstanding chronic inflammation secondary to underlying pathogenic conditions, e.g., hypertension, diabetes mellitus, obstructive sleep apnea, coronary artery disease, atrial fibrillation, morbid obesity, dyslipidemia, and sickle cell disease. Neutrophils can enable, as well as resolve, cerebrovascular inflammation via many effector functions including neutrophil extracellular traps, serine proteases and reactive oxygen species, and pro-resolving endogenous molecules such as Annexin A1. Like neutrophils, platelets also engage in pro- as well as anti-inflammatory roles in regulating cerebrovascular inflammation. These anucleated cells are at the core of stroke pathogenesis and can trigger an ischemic event via adherence to the hypoxic cerebral endothelial cells culminating in aggregation and clot formation. In this article, we review and highlight the evolving role of neutrophils and platelets in ischemic stroke and discuss ongoing preclinical and clinical strategies that may produce viable therapeutics for prevention and management of stroke.
\end{abstract}

Keywords: neutrophils; platelets; stroke; annexin A1; resolution; thromboinflammation

\section{Introduction}

The understanding and the therapeutic approach to stroke has remarkably transformed in the past few decades [1]. Globally, there were approximately 6.6 million deaths attributable to stroke in 2019, which increased by 12.2\% since 2010 [2]. Approximately 800,000 Americans annually suffer from stroke-related morbidity, and mortality with ischemic stroke (IS) being the most common etiology followed by hemorrhagic stroke type [2]. The recent advent of hyper-acute endovascular therapy (EVT) for large vessel occlusion in IS in the form of mechanical thrombectomy has further enhanced the neurological care and recovery [3]. The hyperacute time for the critical management of IS relies on prompt recognition of the diagnosis and urgent reperfusion/recanalization strategies. Secondary prevention strategies focus on cardiovascular and metabolic risk management such as blood pressure, glucose, cholesterol, and antithrombotic therapies.

Neutrophils and platelets are key players in ischemic brain injury and its resolution [4-7]. Resolution is the physiological ability of the body to achieve homeostasis after infection or inflammation. However, in chronic inflammation, where there is an excessive and persistent inflammatory response, the process of resolution is hampered $[8,9]$. Acute cerebral ischemia induces a strong immune response resulting in recruitment of several subsets of leukocytes (mainly neutrophils), activation of platelets, and coagulation cascade and upregulation of cell adhesion molecules and cytokines [10]. Neutrophils and platelets are known for their ability to produce proinflammatory/prothrombotic mediators, thereby forming an important link between inflammation and thrombosis, a phenomenon referred to as "thromboinflammation" $[4,11,12]$. The concept of thromboinflammation in stroke 
pathophysiology has gained considerable attention and traction in the last decade [4,12]. Furthermore, understanding the complex and important roles that both neutrophils and platelets play in the pathophysiology of IS continues to be a main research focus for drug discovery programs focused on finding potential therapeutics to protect against IS and for the management post-IS [10,13].

Neutrophil-platelet aggregate (NPA) formation is a well-known phenomenon and is the center of the pathogenesis of cerebral thrombus formation (Figure 1) [14]. Neutrophilderived P-selectin glycoprotein ligand-1 (PSGL-1) and platelet P-selectin drive NPA development resulting in the activation Mac-1and LFA-1 (Mac-1 and LFA-1 are two $\beta 2$ integrins expressed on neutrophils and mediate the recruitment cascade by binding to intercellular adhesive molecule 1 (ICAM-1)) [15,16]. In vivo, NPAs are also facilitated by margination of platelets and neutrophils to the periphery of blood vessels as a consequence of displacement of erythrocytes to the central part of the vessels [17]. Ischemia-reperfusion injury (I/RI), which is one of the main underlying causes of IS pathogenesis [5,18,19], further enables NPA formation and amplifies thromboinflammatory responses in IS [7,20] (Figure 2).
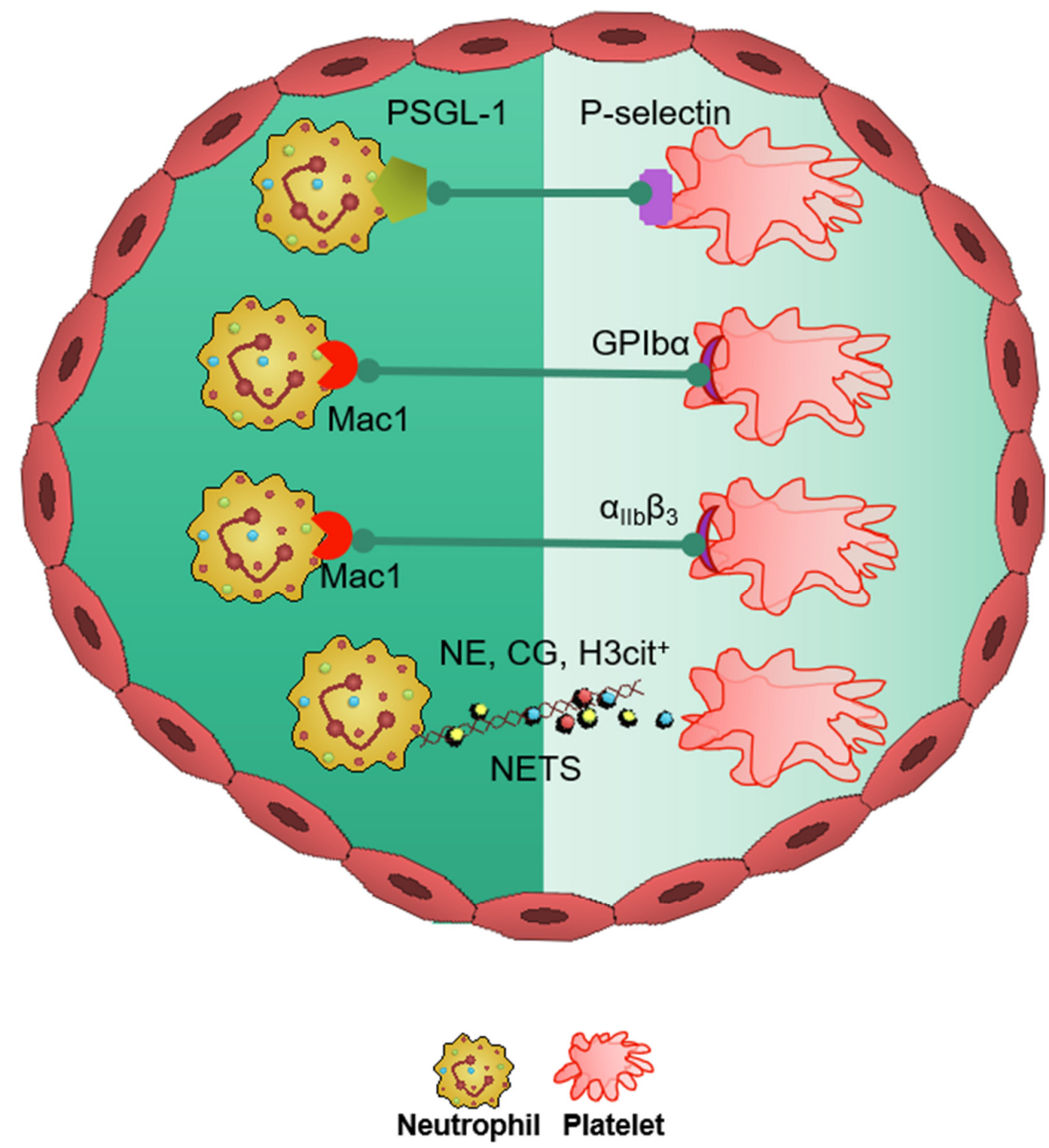

Figure 1. Neutrophil-platelet interactions in cerebral thromboinflammation. This figure shows the major neutrophil-platelet interactions (P-selectin glycoprotein ligand-1 [PSGL]-1-P-selectin, Mac-1GPIb $\alpha$, and Mac-1- $\alpha_{I I b} \beta_{3}$ ) in cerebral thromboinflammation. Neutrophils also interact with platelets via productions of NETs, which are laden with various pro-thrombotic mediators such as neutrophil elastase (NE), cathepsin G (CG) and $\mathrm{H}_{3} \mathrm{cit}^{+}$(citrullinated histone $\mathrm{H} 3$ ). 


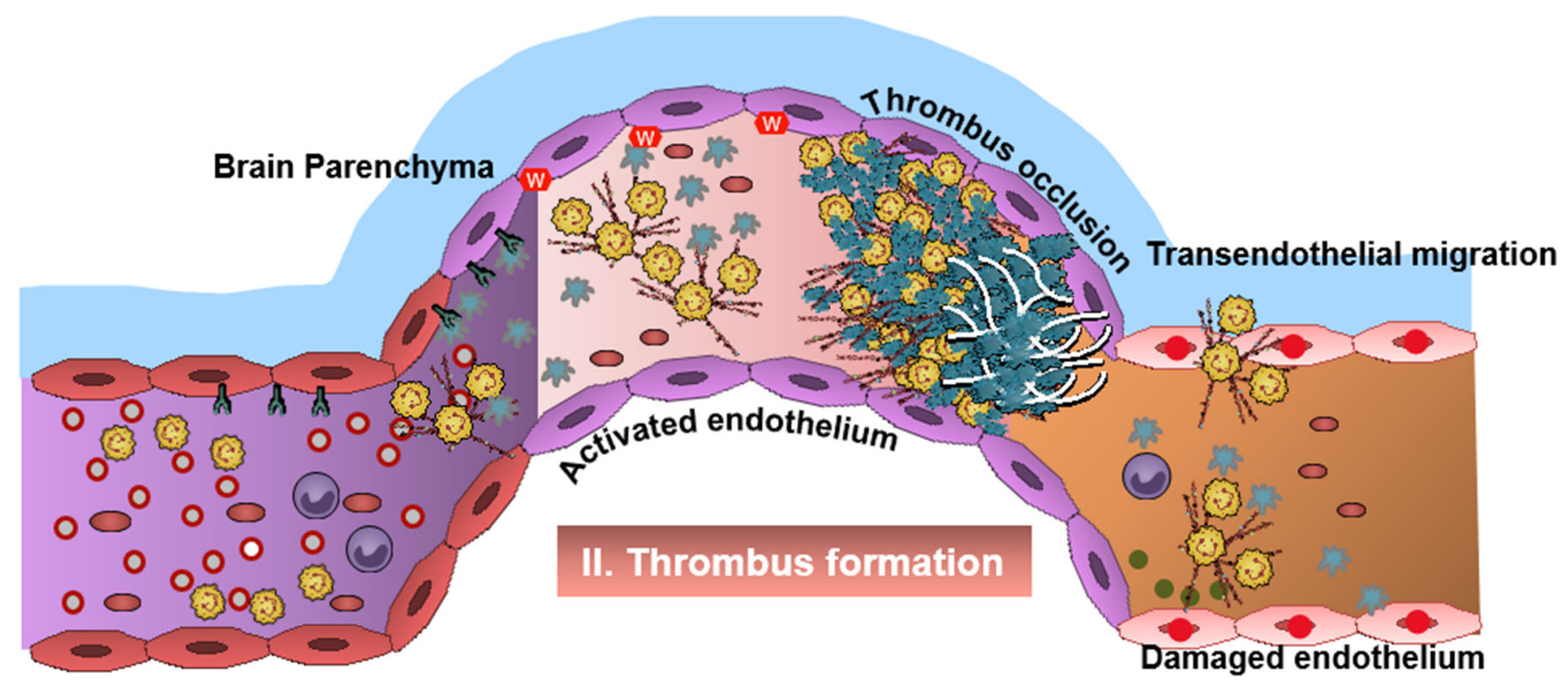

I. Cellular activation

III. Reperfusion Injury and recruitment

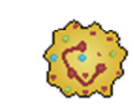

Neutrophil

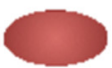

RBC
00

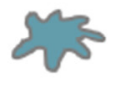

Resting platelet

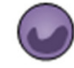

Monocyte

\section{Activated platelet}

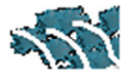

Activated platelet + Fibrin

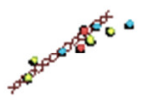

NETs

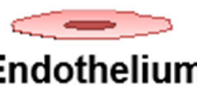

\section{A $A$ CAMs ROS}

Figure 2. Role of neutrophil-platelet interactions in pathogenesis of stroke. (I) Cellular activation and recruitment. Under thromboinflammatory stress with underlying chronic inflammation there is increased recruitment and activation of cellular milieu including neutrophils and platelets into the cerebral blood vessels. This is further assisted by activation and release of cell adhesion molecules (CAMs), such as intracellular adhesion molecule and vascular adhesion molecule, and P and E selectin resulting in neutrophil activation, adherence, and rolling along the activated endothelium. Neutrophils on activation start producing various pro-thrombotic mediators such as neutrophil extracellular traps, cathepsin G, and neutrophil elastase. (II) Thrombus formation. The above activation and recruitment results in continuous accumulation of stimulated neutrophils, platelets, and red blood cells, and activation of the coagulation cascade. Reactive oxygen species can also enhance the coagulation cascade by inhibiting the tissue factor pathway inhibitor (TFPI). Neutrophil elastase degradation of TFPI by colocalization on NET surface. (III) Reperfusion injury. Reperfusion results in excessive production of proinflammatory and thrombotic mediators into the vessel distal to the occlusion site, resulting in microvascular dysfunction. Mainly, neutrophils produce reactive oxygen species, which further damage the endothelium and enhance neutrophil transendothelial migration. Additional tissue injury is inflicted by continuous platelet and complement system activation.

\section{Neutrophils in Stroke}

Neutrophils are key players in thromboinflammatory disorders including cardio- and cerebrovascular diseases [21]. These multi-lobed immune cells are amongst the first responders to migrate to the ischemic brain tissue with the zenith of invasion achieved between 48 to $72 \mathrm{~h}$ after ictus [13]. Here, they interact with surrounding cellular milieu including platelets, endothelial cells, microglial cells, and other brain resident cells, producing numerous pro-thrombotic mediators at the local inflammatory tissue. 
The central nervous system is an immune-privileged sanctuary in which inflammatory milieu is tightly regulated to protect the neural cells from any immune response, injury, and/or death [22,23]. Neutrophils are usually restricted from trafficking into the brain parenchyma and cerebrospinal fluid (CSF) by the presence of the blood-brain barrier (BBB) [24]. Neuroinflammation seen in acute IS results in damage of BBB, making it easier for immune cells to transmigrate into the brain, with cytokines such as interleukin-1 playing significant roles in the recruitment and transmigration of neutrophils across the damaged BBB [25].

Early neutrophilia and an increased neutrophil to lymphocyte ratio in patients with IS are associated with larger infarct volumes [26] and worse functional outcomes [27,28]. Neutrophil infiltration to the infarct site is known to further dampen the sterile cerebral environment by increasing the BBB disruption [29]. Additionally, matrix-metalloproteinase (MMP)-9-positive neutrophils in IS are associated with basal lamina type IV collagen degradation and blood extravasation during hemorrhagic transformation [30].

\section{Neutrophil Serine Proteases and Thromboinflammation}

Neutrophil granule serine proteases (NSPs) have been extensively studied in inflammatory pathologies. Amongst NSPs, cathepsin G (CatG) and neutrophil elastase (NE) are particularly known to have thromboinflammatory phenotypes in various inflammatory pathologies [31-35]. NSPs can initiate and promote thromboinflammation in stroke by interacting with platelets and coagulation factors [11] and binding with formyl peptide receptors (FPRs) on neutrophils and platelets [32,36].

\section{Neutrophil Extracellular Traps (NETs) and Stroke}

NETosis describes a physiological response of neutrophils, when activated, to produce and extrude complexes of decondensed DNA, termed NETs [37,38]. These NETs are known to not only play a protective role in the immune response against invading pathogens, but they have also been shown to possess pro-inflammatory properties that can promote coagulation and thrombosis leading to and further exacerbating IS [5,39]. NETs are laden with prothrombotic mediators such as $\mathrm{H}_{3} \mathrm{cit}^{+}$(citrullinated histone $\mathrm{H} 3$ ), CatG, NE and myeloperoxidase (MPO) $[4,34]$. Under chronic inflammatory milieu, NETosis can be detrimental and promote acute thromboinflammatory events such as IS [40-43]. Experimental studies in animal models have shown NETs can promote thromboinflammation via different NET components including $\mathrm{H} 3 \mathrm{cit}^{+}$and NSPs [44]. H3cit ${ }^{+}$neutrophils, a pathophysiological hallmark of NETs, have been observed in all ischemic thrombi and more abundant in thrombi of cardioembolic origin compared to other etiologies [41]. Notably, a recent study revealed NETs were significantly higher in the carotid lesion site and were decorated with phosphatidylserine in thrombi [45].

Peptidylarginine deiminase 4 (PAD4) is an enzyme essential for NET formation and is known to be upregulated in thromboinflammatory disorders including IS [46]. In a model of accelerated thromboinflammation such as sickle cell disease (SCD), we found neutrophils from SCD patients increased $\mathrm{H}_{3} \mathrm{Cit}^{+} \mathrm{NETs}$ compared to controls [4]. Furthermore, targeting SCD neutrophils with a pro-resolution molecule Annexin A1(AnxA1) Ac2-26 resulted in decreased $\mathrm{H} 3 \mathrm{Cit}^{+}$NETs from SCD neutrophils and reduced cerebral thrombosis in sickle transgenic mice [4].

\section{Neutrophil-Dependent Oxidative Stress and IS}

Neutrophils are rich sources of reactive oxygen species (ROS) and can contribute to harmful oxidative stress, which can further accelerate thromboinflammation. ROS production in the peri-infarct area has a major role in the pathogenesis of ischemic- and reperfusion-related brain injury $[47,48]$. ROS regulates neutrophil recruitment during inflammation by mainly inducing expression of adhesion molecules, such as vascular cell adhesion molecule-1 (VCAM-1), and can facilitate the opening of intercellular passageways to help neutrophils transmigrate to the inflammatory tissue [49]. There are multiple 
studies that have shown that targeting ROS production may attenuate oxidative stress and inflammation, reduce edema, and help to maintain the function and integrity of the BBB [50]. Remote ischemic conditioning and hypothermia can also attenuate oxidant stress-induced inflammation, and non-pharmacologic adjunctive ROS-targeting therapies are currently being tested to augment neurovascular protection in IS [51,52]. ROS can also enhance thromboinflammation by inhibiting the tissue factor pathway inhibitor (TFPI), which is the only physiologic inhibitor of TF activity [53].

\section{Platelets in Stroke}

Platelets are small anucleated multifaceted cells that are released from megakaryocytes [54,55], and from the bone marrow and lungs [56,57]. Their primary function is regulating hemostasis and thrombosis [58], although more recently they have been shown to play important roles in inflammation [59]. However, there is a delicate balance between the physiological and pathophysiological role of platelets due to their mediation of complex vascular responses in innate and adaptive immunity [60]. Therefore, over the years the pathophysiologic role of platelets has been studied extensively in thrombotic disorders such as myocardial infarction (MI), IS, and venous thromboembolism. This has led to the advancement of antiplatelets and anticoagulant therapies in thromboinflammatory conditions such as coronary artery disease, atrial fibrillation, and stroke [61]. Platelet production from the bone marrow is regulated by physiological homeostasis but can be adversely affected in pathophysiological conditions [59]. Thrombopoietin, secreted by the liver, is the primary growth factor and chief regulator of megakaryocytes for the platelet production, signaling via its receptor, MPL [62].

In the neurovasculature, there are distinct mechanisms of platelet-mediated thromboinflammation, which involves interaction with the neutrophils, endothelial cells, plasmatic coagulation factors, and the complement system [63,64]. In stroke, platelets and neutrophils are the first immunomodulatory cells recruited to the affected cerebral vessel where they initiate aggregation and thrombus formation [63]. The interaction of the platelets with the surrounding milieu, including circulating neutrophils, plays a significant role in regulating thromboinflammation $[7,12,64]$. Platelets express P-selectin on activation, which interacts with PSGL-1 to enhance neutrophil activation and recruitment at the inflammatory site. The CD40 ligand (CD40L) is found on platelets and is released on activation in the soluble circulating form, thus inducing endothelial cells to secrete chemokines and express adhesion molecules, thereby initiating a vascular inflammatory response. CD40L is also a key regulator of NPA formation and can accelerate early stages of atherosclerosis and plaque development, promote progression toward advanced atherosclerosis; and influence regulatory $\mathrm{T}$ cell recruitment in atherosclerosis, which is one of the main underlying causes of stroke pathogenesis [65]. Platelet PF4-dependent HIT can result in NPA formation and the development of thrombi enabling the pathogenesis of stroke [43].

Damage-associated molecular pattern molecule high-mobility group box 1 (HMGB1) is upregulated by activated platelets in multiple inflammatory diseases and has also been shown to be a critical mediator of thrombosis by regulating platelet activation, granular secretion, adhesion, and spreading [66]. HMGB1 effects on platelets seems to be mediated via platelet toll-like receptor 4 (TLR4) followed by MyD88/GC complex formation and activation of the cGMP-dependent protein kinase I (cGKI) [66]. Interestingly, platelet TLR4 also activates NET production, which can further enable stroke pathogenesis [67].

Platelet activation and aggregation resulting in thrombosis is further influenced by the high shear forces generated from the blood flow around the thrombus microenvironment [68]. The von Willebrand factor (vWF) is a key participant in the platelet-dependent thromboinflammation and stroke development [69]. Shear stress activates and brings conformational change to vWF, which then associates with platelet GPIb $\alpha$ (a subunit of GPIb-IX-V complex). This vWF-GPIb $\alpha$ interaction is crucial for initial platelet adhesion, which in turn facilitates platelet aggregation and adhesion in thrombotic events $[70,71]$. vWF-GPIb $\alpha$ interaction leads to platelet activation and results in soluble platelet agonists, 
such as adenosine $5^{\prime}$-diphosphate, adenosine $5^{\prime}$-triphosphate, and thromboxane $\mathrm{A}_{2}\left(\mathrm{TXA}_{2}\right)$, being released at the inflammatory site and shifting GPIIb/IIIa to a high-affinity state and further enabling both thrombus formation [69] and increasing the risk of IS and secondary thrombotic events post -IS [6]. Interestingly, a recent study showed that PAD4 in circulation enhances thrombosis by promoting formation of vWF-platelet string formation and reducing ADAMST13 activity [72].

\section{Neutrophil- and Platelet-Dependent AnxA1-FPR2/ALX Resolution Axis in Stroke}

Inflammation plays a key role in the pathophysiology of IS. Resolution is the ideal outcome of inflammation $[4,73,74]$, and is defined as the mechanism to clear inflammatory influx to restore functional homeostasis. Resolution involves a tightly regulated series of events that are mediated by specialized pro-resolving mediators (SPMs) (e.g., resolvins, lipoxins, maresins, and protectins) and resolver proteins (e.g., Annexin 1 and Annexin 1-derived peptides) (10,60-65), which are actively involved in the recovery phase of inflammation in acute and chronic conditions $(8,61,66-68)$. AnxA1 and its biomimetic peptide AnxA1 $1_{\mathrm{Ac} 2-26}$ have a more unique role in the resolution axis as they can target both endogenous inflammatory and pro-resolving pathways [75]. It is known that resolution is dampened in chronic inflammatory states, as shown for example by decreased levels of AnxA1 in plasma samples obtained from patients with SCD or IS compared to their respective controls [4,6]. The resolution process has also been shown to be altered or dysregulated in other inflammatory conditions, including MI, chronic kidney disease, and arthritis [6,76-80]. A new phase that follows resolution is known as 'post-resolution' in which the affected tissue develops adaptive immunity. In chronic inflammation, the post-resolution phase is not achieved due to stagnant or 'frustrated resolution' resulting in a delay in adaptive immunity [81]. The current research and development of novel pharmacological strategies may help in rescuing resolution biology in chronic inflammatory conditions, which in turn may help to prevent acute cerebrovascular events such as IS.

\section{Therapeutics in Thromboinflammation}

Due to the understanding of thromboinflammatory mechanisms in the evolution of IS, there has been significant research in drug development programs targeting neutrophiland platelet-dependent mediators: In pre-clinical studies, engagement of the AnxA1FPR2/ALX pathway in neutrophils as well as platelets produced significant results of mitigation and rescue of the adverse thromboinflammatory phenotype in cerebral microvessels, theoretically preventing the onset of IS as well as management of secondary I/RI-related inflammation (Figure 3) $[4,6,7,75,82]$. 

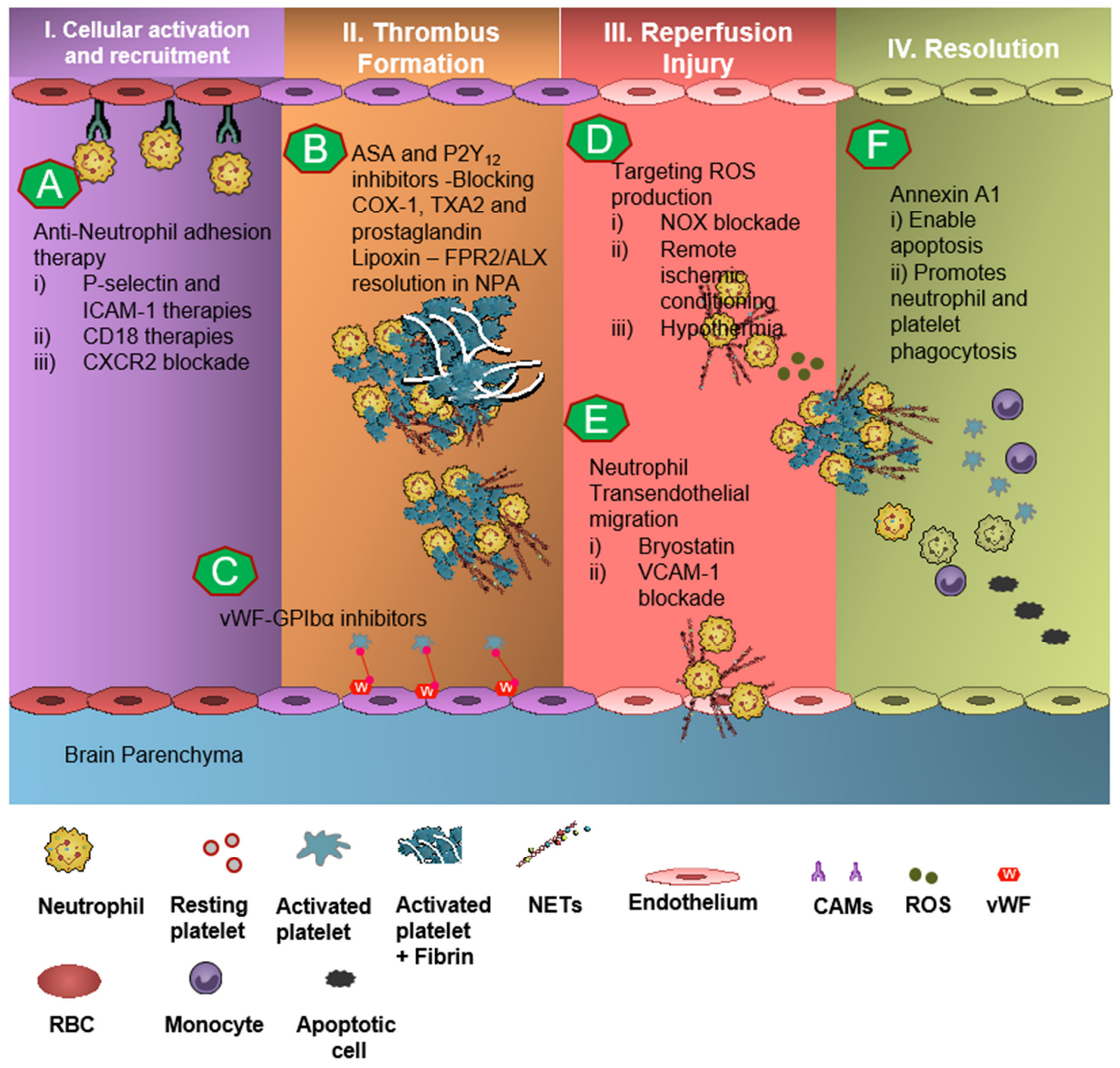

Figure 3. Targeting neutrophil- and platelet-dependent thromboinflammation in stroke. Schematic depiction of potential therapeutic targets to mitigate thromboinflammation in stroke. (A) Anti-neutrophil adhesion agents include P-selectin and intracellular adhesion molecule-1 (ICAM-1) therapies, CD18, and CXCR2 blockade. (B) Aspirin (ASA) and P2Y 12 inhibition (clopidogrel and ticagrelor) inhibit the platelet activation and aggregation by antagonizing the platelet $\mathrm{P}_{2} \mathrm{Y}_{12}$ receptor. Lipoxin, an endogenous pro-resolving molecule, engages via Formyl peptide receptor-2/lipoxin- $\mathrm{A}_{4}$ (Fpr2/ ALX) pathway and modifies neutrophil-platelet aggregate response resulting in anti-inflammatory and pro-resolving response in stroke. (C) Targeting von-Willebrand factor (vWF)-GPIb $\alpha$ interaction attenuates vWF-mediated platelet adhesion. (D) Targeting reactive oxygen species production by nicotinamide adenine dinucleotide phosphate (NADPH) oxidase (NOX) blockade or remote ischemic conditioning and hypothermia may attenuate oxidative stress and inflammation, reduce edema, and help to maintain the function and integrity of the blood-brain barrier (BBB) and augment neurovascular protection in stroke. (E) Bryostatin and vascular cell adhesion molecule (VCAM-1) blockade can inhibit neutrophil transendothelial migration. (F) Annexin A1 (AnxA1) and related biomimetic peptides such as Annexin A1 Ac2-26 engage via AnxA1-Fpr2-ALX by reducing neutrophil activation and the release of pro-thrombotic mediators, regulating neutrophil $\mathrm{H} 3 \mathrm{cit}^{+}{ }^{+}$Citrullinated $^{-}$ histone $\mathrm{H} 3$ ) production, and lastly enabling of neutrophil and platelet phagocytosis. 


\section{Targeting Neutrophil-Dependent Thromboinflammation}

Neutrophils are the main agents of chaos in cerebral thromboinflammation and promote thrombosis and atherosclerosis via the release of various thromboinflammatory mediators as discussed above. Therefore, targeting thromboinflammatory mediators may have a critical role in management of IS by suppressing the inflammatory process and boosting neuroprotection.

Neutrophil recruitment to the ischemic site and adhesion to brain endothelial cells is enabled by P-selectin and ICAM-1 [83-85]. The anti-neutrophil adhesion strategy targeting P-selectin and ICAM-1 was proven to diminish neutrophil recruitment and transmigration at the site of cerebral I/R, thereby resulting in attenuation of thromboinflammation $[84,85]$. CD18 (leukocyte counter-ligand to endothelial intracellular adhesion molecule-1) knockout mice conferred cerebrovascular protection in a murine model of IS, but not to CD18-deficient animals with permanent middle cerebral artery occlusion, suggesting anti-neutrophil adhesion strategies should be further tested for the management of stroke [84]. However, Enlimomab, a murine ICAM-1 antibody that is known to reduce leukocyte adhesion and infarct size in experimental stroke studies, was not effective in earlier clinical trials, with more adverse events such as infections and fever compared to the placebo [86]. Studies targeting anti-E-selectin, anti-L-selectin, and chemokine receptors had no response to minimal response in animal models of experimental IS [13].

Neutrophil recruitment to the site of inflammation and stroke can result in excessive production of NSPs and reactive oxygen species (ROS), damaging the vascular as well as parenchymal structures by acting at various steps of the inflammatory cascade. Directly targeting the production of NSPs or using intracellular protease inhibitor was shown to attenuate NSP-dependent thromboinflammation [31,35]. Whereas targeting ROS production can attenuate initial as well as later stages of oxidative stress development in stroke by mitigating I/RI, restoring the BBB, and preventing neuronal death [50]. In our own work, we have shown that targeting neutrophil-dependent nicotinamide adenine dinucleotide phosphate (NADPH) oxidase may attenuate cerebrovascular thromboinflammation by inhibiting the production of $\mathrm{H} 3 \mathrm{cit}^{+}$neutrophils [87].

IS induces BBB permeability, thereby increasing the movement of inflammatory cells, such as neutrophils, into the brain. Enhancing and protecting the BBB against IS damage is a target of IS treatment. Bryostatin, a macrolide lactone, has been described to activate PKC $\delta$ in endothelial cells, enhance barrier integrity, block cytokine-induced barrier alterations, and potentially block neutrophil transendothelial migration $[88,89]$. Bryostatin treatment in an experimental model of IS resulted in improved neurological function, reduced lesion volume, and salvaged tissue compared to controls by reducing necrosis and peri-infarct astrogliosis [90].

Finally, knowing the role of NETs and PAD4 in the pathogenesis of stroke, targeting pathological NET production may be a viable approach to reduce thrombosis and stroke damage $[4,87]$. Our own findings have demonstrated that targeting H3cit ${ }^{+}$NETs and PAD4 significantly inhibited cerebral thrombosis in vivo $[4,87]$. However, at present, few clinical trials have tested NET or PAD4 inhibitors in stroke management.

\section{Targeting Platelet-Dependent Thromboinflammation}

Acetylsalicylic acid (ASA), commonly known as aspirin, is one of the most common medications prescribed for primary, as well as secondary prevention of cardiovascular disease and in stroke thromboprophylaxis [91]. ASA produces clinical effect by irreversibly acetylating the active site of cyclooxygenase- 1 (COX-1), thereby blocking prostaglandin and $\mathrm{TXA}_{2}$ synthesis, which are required for thrombus formation [92]. In a preclinical study, ASA significantly reduced cerebral leukocyte recruitment and increased endogenous levels of aspirin-triggered lipoxin, thereby inducing thromboinflammation resolution via FPR2/ALX pathway [7]. Multiple clinical trials have reported long-term secondary prevention of stroke in patients with transient of attack or IS, including non-randomized observation studies reporting a benefit of up to $80 \%$ risk reduction in recurrent stroke [91,93]. 
$\mathrm{P}_{2} \mathrm{Y}_{12}$ receptor is the main receptor responsible for ADP-stimulated activation of the glycoprotein IIb/IIIa receptor. Thienopyridines such as clopidogrel and ticagrelor inhibit the platelet activation and aggregation by antagonizing the platelet $\mathrm{P}^{2} \mathrm{Y}_{12}$ receptor [94]. Multiple clinical trials have shown the benefit of dual- as well as monotherapy with P2Y 12 inhibition in stroke [95]. CHANCE and POINT revealed that the combination of clopidogrel and aspirin reduced risk of stroke in the first 90 days in patients with minor ischemic stroke or high-risk TIA, compared to those who received aspirin alone $[96,97]$. In a similar fashion, THALES and SOCRATES showed the benefit of ticagrelor with and without aspirin $[98,99]$. The recently published CHANCE-2 trial found that, in patients with minor ischemic stroke or TIA who are carriers of CYP2C19 loss-of-function alleles, the risk of stroke at 90 days was modestly lower in patients who received ticagrelor compared to clopidogrel $[95,100]$.

Dipyridamole inhibits adenosine deaminase and platelet cAMP phosphodiesterase resulting in prevention of platelet aggregation. Multiple clinical trials have studied combination dipyridamole and aspirin for stroke management, especially the ESPS-2 trial, which showed the benefit of $25 \mathrm{mg}$ of ASA twice daily and dipyridamole as equally effective for the secondary prevention of stroke and TIA [101].

Many case studies have investigated and revealed an association between high vWF levels [102] and low levels of ADAMSTS13 [103] in patients with IS. Therefore, several clinical studies have utilized strategies to inhibit vWF or enhance ADAMSTS13 in the management of stroke, including in knockout transgenic animals [69]. Most of the inhibitors targeting vWF-mediated platelet adhesion target vWF-GPIb $\alpha$ interaction, and are still in pre-clinical stages [104]. vWF inhibitors include monoclonal antibodies targeting vWF (e.g., 82D6A3, AJvW2, and AJW200) or targeting GPIb $\alpha$ 6B4 (e.g., h6B4, the nanobody ALX-0081, the aptamer ARC1779, and the recombinant GPIb $\alpha$ fragment GPG-290) [69].

\section{Concluding Remarks and Future Directions}

Neutrophils and platelets are seen as key players in thromboinflammation and the pathogenesis of stroke. The emerging role of neutrophil-derived serine proteases, extracellular traps, and ROS in the cerebrovascular thromboinflammation has created an immense opportunity for the development of translational research. Current evidence suggests the dampening of resolution pathways/mediators in thromboinflammatory conditions such as stroke, therefore leading to an unchecked and persistent burden of pro-inflammatory milieu. The ongoing research including our own will be instrumental in developing viable drug discovery programs that target proteins and pathways involved in pathophysiological settings (such as $\mathrm{H}_{3} \mathrm{Cit}^{+}$NETs and PAD4) to enable inflammation resolution. In a similar fashion, platelet-dependent thromboinflammation has and can be effectively targeted by inhibiting the pathophysiological activation of vWF-GPIb $\alpha$ interaction, $\mathrm{P} 2 \mathrm{Y}_{12}, \mathrm{CD} 40 \mathrm{~L}$, and TLR4. Additional targeting and modulating NPA formation can mitigate the secondary complications of chronic thromboinflammation such as stroke. Finally, exploiting endogenous protective mechanisms and pathways (e.g., the AnxA1/FPR2/ALX pathway) in neutrophils and platelets, thereby enabling the resolution of thromboinflammation, is going to be impactful in developing novel and potent therapies against stroke and will help drive effective pre-clinical and clinical therapeutic studies.

Author Contributions: Conceptualization: J.A. and F.N.E.G. Formal Analysis: J.A. and F.N.E.G. Resources: J.A. and F.N.E.G. Writing-Original Draft Preparation: J.A. Writing-Review and Editing: J.A. and F.N.E.G. Visualization: J.A. and F.N.E.G. Supervision: J.A. and F.N.E.G. Project Administration: J.A. and F.N.E.G. All authors have read and agreed to the published version of the manuscript.

Funding: This research received no external funding.

Institutional Review Board Statement: Not applicable.

Informed Consent Statement: Not applicable.

Data Availability Statement: Not applicable. 
Acknowledgments: FNEG acknowledges the support of The Royal Society Wolfson Foundation: RSWF $\backslash R 3 \backslash 183001$.

Conflicts of Interest: The authors declare no conflict of interest.

\section{References}

1. Broderick, J.P.; Hill, M.D. Advances in Acute Stroke Treatment 2020. Stroke 2021, 52, 729-734. [CrossRef]

2. Virani, S.S.; Alonso, A.; Aparicio, H.J.; Benjamin, E.J.; Bittencourt, M.S.; Callaway, C.W.; Carson, A.P.; Chamberlain, A.M.; Cheng, S.; Delling, F.N.; et al. Heart Disease and Stroke Statistics-2021 Update: A Report From the American Heart Association. Circulation 2021, 143, e254-e743. [CrossRef]

3. Silva, G.S.; Nogueira, R.G. Endovascular Treatment of Acute Ischemic Stroke. Continuum (Minneap Minn) 2020, $26,310-331$. [CrossRef]

4. Ansari, J.; Senchenkova, E.Y.; Vital, S.A.; Al Yafeai, Z.; Kaur, G.; Sparkenbaugh, E.M.; Orr, A.; Pawlinski, R.; Hebbel, R.P.; Granger, D.N.; et al. Targeting AnxA1/Fpr2/ALX Pathway Regulates Neutrophil Function Promoting Thrombo-Inflammation Resolution in Sickle Cell Disease. Blood 2021, 137, 1538-1549. [CrossRef]

5. Ansari, J.; Gavins, F.N.E. The impact of thrombo-inflammation on the cerebral microcirculation. Microcirculation 2021, 28 , e12689. [CrossRef] [PubMed]

6. Senchenkova, E.Y.; Ansari, J.; Becker, F.; Vital, S.A.; Al-Yafeai, Z.; Sparkenbaugh, E.M.; Pawlinski, R.; Stokes, K.Y.; Carroll, J.L.; Dragoi, A.M.; et al. A Novel Role for the AnxA1-Fpr2/ALX Signaling Axis as a Key Regulator of Platelet Function to Promote Resolution of Inflammation. Circulation 2019, 140, 319-335. [CrossRef]

7. Vital, S.A.; Becker, F.; Holloway, P.M.; Russell, J.; Perretti, M.; Granger, D.N.; Gavins, F.N. Formyl-Peptide Receptor 2/3/Lipoxin A4 Receptor Regulates Neutrophil-Platelet Aggregation and Attenuates Cerebral Inflammation: Impact for Therapy in Cardiovascular Disease. Circulation 2016, 133, 2169-2179. [CrossRef] [PubMed]

8. Perretti, M.; Leroy, X.; Bland, E.J.; Montero-Melendez, T. Resolution Pharmacology: Opportunities for Therapeutic Innovation in Inflammation. Trends Pharmacol. Sci. 2015, 36, 737-755. [CrossRef] [PubMed]

9. Serhan, C.N. Pro-resolving lipid mediators are leads for resolution physiology. Nature 2014, 510, 92-101. [CrossRef]

10. Stoll, G.; Kleinschnitz, C.; Nieswandt, B. Combating innate inflammation: A new paradigm for acute treatment of stroke? Ann. N. Y. Acad. Sci. 2010, 1207, 149-154. [CrossRef]

11. Massberg, S.; Grahl, L.; von Bruehl, M.L.; Manukyan, D.; Pfeiler, S.; Goosmann, C.; Brinkmann, V.; Lorenz, M.; Bidzhekov, K.; Khandagale, A.B.; et al. Reciprocal coupling of coagulation and innate immunity via neutrophil serine proteases. Nat. Med. 2010, 16, 887-896. [CrossRef]

12. De Meyer, S.F.; Denorme, F.; Langhauser, F.; Geuss, E.; Fluri, F.; Kleinschnitz, C. Thromboinflammation in Stroke Brain Damage. Stroke 2016, 47, 1165-1172. [CrossRef]

13. Jickling, G.C.; Liu, D.; Ander, B.P.; Stamova, B.; Zhan, X.; Sharp, F.R. Targeting neutrophils in ischemic stroke: Translational insights from experimental studies. J. Cereb. Blood Flow Metab. 2015, 35, 888-901. [CrossRef]

14. Cerletti, C.; Tamburrelli, C.; Izzi, B.; Gianfagna, F.; de Gaetano, G. Platelet-leukocyte interactions in thrombosis. Thromb. Res. 2012, 129, 263-266. [CrossRef] [PubMed]

15. Arumugam, T.V.; Salter, J.W.; Chidlow, J.H.; Ballantyne, C.M.; Kevil, C.G.; Granger, D.N. Contributions of LFA-1 and Mac-1 to brain injury and microvascular dysfunction induced by transient middle cerebral artery occlusion. Am. J. Physiol. Heart Circ. Physiol. 2004, 287, H2555-H2560. [CrossRef] [PubMed]

16. Li, N.; Mao, D.; Lü, S.; Tong, C.; Zhang, Y.; Long, M. Distinct binding affinities of Mac-1 and LFA-1 in neutrophil activation. J. Immunol. 2013, 190, 4371-4381. [CrossRef] [PubMed]

17. Goldsmith, H.L.; Spain, S. Margination of leukocytes in blood flow through small tubes. Microvasc. Res. 1984, $27,204-222$. [CrossRef]

18. Enzmann, G.; Kargaran, S.; Engelhardt, B. Ischemia-reperfusion injury in stroke: Impact of the brain barriers and brain immune privilege on neutrophil function. Ther. Adv. Neurol. Disord. 2018, 11, 1756286418794184. [CrossRef]

19. Ansari, J.; Gavins, F.N.E. Ischemia-Reperfusion Injury in Sickle Cell Disease: From Basics to Therapeutics. Am. J. Pathol. 2019, 189, 706-718. [CrossRef]

20. Ritter, L.S.; Stempel, K.M.; Coull, B.M.; McDonagh, P.F. Leukocyte-platelet aggregates in rat peripheral blood after ischemic stroke and reperfusion. Biol. Res. Nurs. 2005, 6, 281-288. [CrossRef]

21. Noubouossie, D.F.; Reeves, B.N.; Strahl, B.D.; Key, N.S. Neutrophils: Back in the thrombosis spotlight. Blood 2019, 133, $2186-2197$. [CrossRef]

22. Harris, M.G.; Hulseberg, P.; Ling, C.; Karman, J.; Clarkson, B.D.; Harding, J.S.; Zhang, M.; Sandor, A.; Christensen, K.; Nagy, A.; et al. Immune privilege of the CNS is not the consequence of limited antigen sampling. Sci. Rep. 2014, 4, 4422. [CrossRef]

23. Ousman, S.S.; Kubes, P. Immune surveillance in the central nervous system. Nat. Neurosci. 2012, 15, 1096-1101. [CrossRef]

24. Manda-Handzlik, A.; Demkow, U. The Brain Entangled: The Contribution of Neutrophil Extracellular Traps to the Diseases of the Central Nervous System. Cells 2019, 8, 1477. [CrossRef]

25. Allen, C.; Thornton, P.; Denes, A.; McColl, B.W.; Pierozynski, A.; Monestier, M.; Pinteaux, E.; Rothwell, N.J.; Allan, S.M. Neutrophil cerebrovascular transmigration triggers rapid neurotoxicity through release of proteases associated with decondensed DNA. J. Immunol. 2012, 189, 381-392. [CrossRef] [PubMed] 
26. Buck, B.H.; Liebeskind, D.S.; Saver, J.L.; Bang, O.Y.; Yun, S.W.; Starkman, S.; Ali, L.K.; Kim, D.; Villablanca, J.P.; Salamon, N.; et al. Early neutrophilia is associated with volume of ischemic tissue in acute stroke. Stroke 2008, 39, 355-360. [CrossRef] [PubMed]

27. Quan, K.; Wang, A.; Zhang, X.; Meng, X.; Chen, P.; Li, H.; Wang, Y. Neutrophil to lymphocyte ratio and adverse clinical outcomes in patients with ischemic stroke. Ann. Transl. Med. 2021, 9, 1047. [CrossRef] [PubMed]

28. Ying, Y.; Yu, F.; Luo, Y.; Feng, X.; Liao, D.; Wei, M.; Li, X.; Huang, Q.; Liu, Z.; Zhang, L.; et al. Neutrophil-to-Lymphocyte Ratio as a Predictive Biomarker for Stroke Severity and Short-Term Prognosis in Acute Ischemic Stroke With Intracranial Atherosclerotic Stenosis. Front. Neurol. 2021, 12, 705949. [CrossRef]

29. Jiang, X.; Andjelkovic, A.V.; Zhu, L.; Yang, T.; Bennett, M.V.L.; Chen, J.; Keep, R.F.; Shi, Y. Blood-brain barrier dysfunction and recovery after ischemic stroke. Prog. Neurobiol. 2018, 163-164, 144-171. [CrossRef] [PubMed]

30. Rosell, A.; Cuadrado, E.; Ortega-Aznar, A.; Hernandez-Guillamon, M.; Lo, E.H.; Montaner, J. MMP-9-positive neutrophil infiltration is associated to blood-brain barrier breakdown and basal lamina type IV collagen degradation during hemorrhagic transformation after human ischemic stroke. Stroke 2008, 39, 1121-1126. [CrossRef]

31. Faraday, N.; Schunke, K.; Saleem, S.; Fu, J.; Wang, B.; Zhang, J.; Morrell, C.; Dore, S. Cathepsin G-dependent modulation of platelet thrombus formation in vivo by blood neutrophils. PLoS ONE 2013, 8, e71447. [CrossRef] [PubMed]

32. Woloszynek, J.C.; Hu, Y.; Pham, C.T. Cathepsin G-regulated release of formyl peptide receptor agonists modulate neutrophil effector functions. J. Biol. Chem. 2012, 287, 34101-34109. [CrossRef]

33. Papayannopoulos, V.; Staab, D.; Zychlinsky, A. Neutrophil elastase enhances sputum solubilization in cystic fibrosis patients receiving Dnase therapy. PloS ONE 2011, 6, e28526. [CrossRef] [PubMed]

34. Pham, C.T. Neutrophil serine proteases: Specific regulators of inflammation. Nat. Rev. Immunol. 2006, 6, 541-550. [CrossRef]

35. Burgener, S.S.; Leborgne, N.G.F.; Snipas, S.J.; Salvesen, G.S.; Bird, P.I.; Benarafa, C. Cathepsin G Inhibition by Serpinb1 and Serpinb6 Prevents Programmed Necrosis in Neutrophils and Monocytes and Reduces GSDMD-Driven Inflammation. Cell Rep. 2019, 27, 3646-3656. [CrossRef] [PubMed]

36. Sun, R.; Iribarren, P.; Zhang, N.; Zhou, Y.; Gong, W.; Cho, E.H.; Lockett, S.; Chertov, O.; Bednar, F.; Rogers, T.J.; et al. Identification of neutrophil granule protein cathepsin $\mathrm{G}$ as a novel chemotactic agonist for the $\mathrm{G}$ protein-coupled formyl peptide receptor. $J$. Immunol. 2004, 173, 428-436. [CrossRef]

37. Brinkmann, V.; Reichard, U.; Goosmann, C.; Fauler, B.; Uhlemann, Y.; Weiss, D.S.; Weinrauch, Y.; Zychlinsky, A. Neutrophil extracellular traps kill bacteria. Science 2004, 303, 1532-1535. [CrossRef]

38. Fuchs, T.A.; Abed, U.; Goosmann, C.; Hurwitz, R.; Schulze, I.; Wahn, V.; Weinrauch, Y.; Brinkmann, V.; Zychlinsky, A. Novel cell death program leads to neutrophil extracellular traps. J. Cell Biol. 2007, 176, 231-241. [CrossRef] [PubMed]

39. Martinod, K.; Wagner, D.D. Thrombosis: Tangled up in NETs. Blood 2014, 123, 2768-2776. [CrossRef]

40. Fuchs, T.A.; Brill, A.; Duerschmied, D.; Schatzberg, D.; Monestier, M.; Myers, D.D.; Wrobleski, S.K.; Wakefield, T.W.; Hartwig, J.H.; Wagner, D.D. Extracellular DNA traps promote thrombosis. Proc. Natl. Acad. Sci. USA 2010, 107, 15880-15885. [CrossRef]

41. Laridan, E.; Denorme, F.; Desender, L.; Francois, O.; Andersson, T.; Deckmyn, H.; Vanhoorelbeke, K.; De Meyer, S.F. Neutrophil extracellular traps in ischemic stroke thrombi. Ann. Neurol. 2017, 82, 223-232. [CrossRef]

42. Zuo, Y.; Zuo, M.; Yalavarthi, S.; Gockman, K.; Madison, J.A.; Shi, H.; Woodard, W.; Lezak, S.P.; Lugogo, N.L.; Knight, J.S.; et al. Neutrophil extracellular traps and thrombosis in COVID-19. J. Thromb. Thrombolysis 2021, 51, 446-453. [CrossRef] [PubMed]

43. Perdomo, J.; Leung, H.H.L.; Ahmadi, Z.; Yan, F.; Chong, J.J.H.; Passam, F.H.; Chong, B.H. Neutrophil activation and NETosis are the major drivers of thrombosis in heparin-induced thrombocytopenia. Nat. Commun. 2019, 10, 1322. [CrossRef] [PubMed]

44. Mauracher, L.M.; Posch, F.; Martinod, K.; Grilz, E.; Daullary, T.; Hell, L.; Brostjan, C.; Zielinski, C.; Ay, C.; Wagner, D.D.; et al. Citrullinated histone $\mathrm{H} 3$, a biomarker of neutrophil extracellular trap formation, predicts the risk of venous thromboembolism in cancer patients. J. Thromb. Haemost. 2018, 16, 508-518. [CrossRef]

45. Zhou, P.; Li, T.; Jin, J.; Liu, Y.; Li, B.; Sun, Q.; Tian, J.; Zhao, H.; Liu, Z.; Ma, S.; et al. Interactions between neutrophil extracellular traps and activated platelets enhance procoagulant activity in acute stroke patients with ICA occlusion. EbioMedicine 2020, 53, 102671. [CrossRef]

46. Kang, L.; Yu, H.; Yang, X.; Zhu, Y.; Bai, X.; Wang, R.; Cao, Y.; Xu, H.; Luo, H.; Lu, L.; et al. Neutrophil extracellular traps released by neutrophils impair revascularization and vascular remodeling after stroke. Nat. Commun. 2020, 11, 2488. [CrossRef]

47. Chan, P.H. Oxygen radicals in focal cerebral ischemia. Brain Pathol. 1994, 4, 59-65. [CrossRef]

48. Lorenzano, S.; Rost, N.S.; Khan, M.; Li, H.; Batista, L.M.; Chutinet, A.; Green, R.E.; Thankachan, T.K.; Thornell, B.; Muzikansky, A.; et al. Early molecular oxidative stress biomarkers of ischemic penumbra in acute stroke. Neurology 2019, 93, e1288-e1298. [CrossRef] [PubMed]

49. Cook-Mills, J.M.; Marchese, M.E.; Abdala-Valencia, H. Vascular cell adhesion molecule-1 expression and signaling during disease: Regulation by reactive oxygen species and antioxidants. Antioxid. Redox Signal. 2011, 15, 1607-1638. [CrossRef] [PubMed]

50. Rodrigo, R.; Fernandez-Gajardo, R.; Gutierrez, R.; Matamala, J.M.; Carrasco, R.; Miranda-Merchak, A.; Feuerhake, W. Oxidative stress and pathophysiology of ischemic stroke: Novel therapeutic opportunities. CNS Neurol. Disord. Drug Targets 2013, 12, 698-714. [CrossRef] [PubMed]

51. Hoda, M.N.; Siddiqui, S.; Herberg, S.; Periyasamy-Thandavan, S.; Bhatia, K.; Hafez, S.S.; Johnson, M.H.; Hill, W.D.; Ergul, A.; Fagan, S.C.; et al. Remote ischemic perconditioning is effective alone and in combination with intravenous tissue-type plasminogen activator in murine model of embolic stroke. Stroke 2012, 43, 2794-2799. [CrossRef] [PubMed] 
52. Han, Z.; Liu, X.; Luo, Y.; Ji, X. Therapeutic hypothermia for stroke: Where to go? Exp. Neurol. 2015, 272, 67-77. [CrossRef] [PubMed]

53. Ohkura, N.; Hiraishi, S.; Itabe, H.; Hamuro, T.; Kamikubo, Y.; Takano, T.; Matsuda, J.; Horie, S. Oxidized phospholipids in oxidized low-density lipoprotein reduce the activity of tissue factor pathway inhibitor through association with its carboxy-terminal region. Antioxid. Redox Signal. 2004, 6, 705-712. [CrossRef]

54. Demirin, H.; Ozhan, H.; Ucgun, T.; Celer, A.; Bulur, S.; Cil, H.; Gunes, C.; Yildirim, H.A. Normal range of mean platelet volume in healthy subjects: Insight from a large epidemiologic study. Thromb. Res. 2011, 128, 358-360. [CrossRef] [PubMed]

55. Eason, C.T.; Pattison, A.; Howells, D.D.; Mitcheson, J.; Bonner, F.W. Platelet population profiles: Significance of species variation and drug-induced changes. J. Appl. Toxicol. 1986, 6, 437-441. [CrossRef] [PubMed]

56. Daly, M.E. Determinants of platelet count in humans. Haematologica 2011, 96, 10-13. [CrossRef] [PubMed]

57. Lefrancais, E.; Ortiz-Munoz, G.; Caudrillier, A.; Mallavia, B.; Liu, F.; Sayah, D.M.; Thornton, E.E.; Headley, M.B.; David, T.; Coughlin, S.R.; et al. The lung is a site of platelet biogenesis and a reservoir for haematopoietic progenitors. Nature 2017, 544, 105-109. [CrossRef]

58. Koupenova, M.; Clancy, L.; Corkrey, H.A.; Freedman, J.E. Circulating Platelets as Mediators of Immunity, Inflammation, and Thrombosis. Circ. Res. 2018, 122, 337-351. [CrossRef]

59. Margraf, A.; Zarbock, A. Platelets in Inflammation and Resolution. J. Immunol. 2019, 203, 2357-2367. [CrossRef]

60. Pluthero, F.G.; Kahr, W.H.A. The Birth and Death of Platelets in Health and Disease. Physiology (Bethesda) 2018, 33, 225-234. [CrossRef]

61. Michelson, A.D. Antiplatelet therapies for the treatment of cardiovascular disease. Nat. Rev. Drug Discov. 2010, 9, 154-169. [CrossRef] [PubMed]

62. Deutsch, V.R.; Tomer, A. Megakaryocyte development and platelet production. Br. J. Haematol. 2006, 134, 453-466. [CrossRef]

63. Rawish, E.; Nording, H.; Münte, T.; Langer, H.F. Platelets as Mediators of Neuroinflammation and Thrombosis. Front. Immunol. 2020, 11, 548631. [CrossRef]

64. Kehrel, B.E.; Fender, A.C. Resolving Thromboinflammation in the Brain After Ischemic Stroke? Circulation 2016, 133, $2128-2131$. [CrossRef]

65. Lievens, D.; Zernecke, A.; Seijkens, T.; Soehnlein, O.; Beckers, L.; Munnix, I.C.; Wijnands, E.; Goossens, P.; van Kruchten, R.; Thevissen, L.; et al. Platelet CD40L mediates thrombotic and inflammatory processes in atherosclerosis. Blood 2010, 116, $4317-4327$. [CrossRef] [PubMed]

66. Vogel, S.; Bodenstein, R.; Chen, Q.; Feil, S.; Feil, R.; Rheinlaender, J.; Schaffer, T.E.; Bohn, E.; Frick, J.S.; Borst, O.; et al. Plateletderived HMGB1 is a critical mediator of thrombosis. J. Clin. Investig. 2015, 125, 4638-4654. [CrossRef] [PubMed]

67. Clark, S.R.; Ma, A.C.; Tavener, S.A.; McDonald, B.; Goodarzi, Z.; Kelly, M.M.; Patel, K.D.; Chakrabarti, S.; McAvoy, E.; Sinclair, G.D.; et al. Platelet TLR4 activates neutrophil extracellular traps to ensnare bacteria in septic blood. Nat. Med. 2007, 13, 463-469. [CrossRef]

68. Rana, A.; Westein, E.; Niego, B.; Hagemeyer, C.E. Shear-Dependent Platelet Aggregation: Mechanisms and Therapeutic Opportunities. Front. Cardiovasc. Med. 2019, 6, 141. [CrossRef]

69. Meyer, S.F.D.; Stoll, G.; Wagner, D.D.; Kleinschnitz, C. von Willebrand Factor. Stroke 2012, 43, 599-606. [CrossRef]

70. Shankaran, H.; Alexandridis, P.; Neelamegham, S. Aspects of hydrodynamic shear regulating shear-induced platelet activation and self-association of von Willebrand factor in suspension. Blood 2003, 101, 2637-2645. [CrossRef]

71. Li, Y.; Choi, H.; Zhou, Z.; Nolasco, L.; Pownall, H.J.; Voorberg, J.; Moake, J.L.; Dong, J.F. Covalent regulation of ULVWF string formation and elongation on endothelial cells under flow conditions. J. Thromb. Haemost. 2008, 6, 1135-1143. [CrossRef]

72. Sorvillo, N.; Mizurini, D.M.; Coxon, C.; Martinod, K.; Tilvawala, R.; Cherpokova, D.; Salinger, A.J.; Seward, R.J.; Staudinger, C.; Weerapana, E.; et al. Plasma Peptidylarginine Deiminase IV Promotes VWF-Platelet String Formation and Accelerates Thrombosis After Vessel Injury. Circ. Res. 2019, 125, 507-519. [CrossRef]

73. Fullerton, J.N.; Gilroy, D.W. Resolution of inflammation: A new therapeutic frontier. Nat. Rev. Drug Discov. 2016, 15, 551-567. [CrossRef]

74. Serhan, C.N.; Chiang, N.; Van Dyke, T.E. Resolving inflammation: Dual anti-inflammatory and pro-resolution lipid mediators. Nat. Rev. Immunol. 2008, 8, 349-361. [CrossRef]

75. Ansari, J.; Kaur, G.; Gavins, F.N.E. Therapeutic Potential of Annexin A1 in Ischemia Reperfusion Injury. Int. J. Mol. Sci. 2018, 19, 1211. [CrossRef] [PubMed]

76. Kain, V.; Liu, F.; Kozlovskaya, V.; Ingle, K.A.; Bolisetty, S.; Agarwal, A.; Khedkar, S.; Prabhu, S.D.; Kharlampieva, E.; Halade, G.V. Resolution Agonist 15-epi-Lipoxin A4 Programs Early Activation of Resolving Phase in Post-Myocardial Infarction Healing. Sci. Rep. 2017, 7, 9999. [CrossRef] [PubMed]

77. Goicoechea, M.; Sanchez-Nino, M.D.; Ortiz, A.; Garcia de Vinuesa, S.; Quiroga, B.; Bernis, C.; Morales, E.; Fernandez-Juarez, G.; de Sequera, P.; Verdalles, U.; et al. Low dose aspirin increases 15-epi-lipoxin A4 levels in diabetic chronic kidney disease patients. Prostaglandins Leukot. Essent. Fatty Acids 2017, 125, 8-13. [CrossRef]

78. Perucci, L.O.; Sugimoto, M.A.; Gomes, K.B.; Dusse, L.M.; Teixeira, M.M.; Sousa, L.P. Annexin A1 and specialized proresolving lipid mediators: Promoting resolution as a therapeutic strategy in human inflammatory diseases. Expert Opin. Ther. Targets 2017, 21, 879-896. [CrossRef] 
79. Chamani, S.; Bianconi, V.; Tasbandi, A.; Pirro, M.; Barreto, G.E.; Jamialahmadi, T.; Sahebkar, A. Resolution of Inflammation in Neurodegenerative Diseases: The Role of Resolvins. Mediat. Inflamm. 2020, 2020, 3267172. [CrossRef]

80. Patel, H.B.; Kornerup, K.N.; Sampaio, A.L.; D'Acquisto, F.; Seed, M.P.; Girol, A.P.; Gray, M.; Pitzalis, C.; Oliani, S.M.; Perretti, M. The impact of endogenous annexin A1 on glucocorticoid control of inflammatory arthritis. Ann. Rheum. Dis. 2012, 71, $1872-1880$. [CrossRef] [PubMed]

81. Park, J.; Langmead, C.J.; Riddy, D.M. New Advances in Targeting the Resolution of Inflammation: Implications for Specialized Pro-Resolving Mediator GPCR Drug Discovery. ACS Pharmacol. Transl. Sci. 2020, 3, 88-106. [CrossRef] [PubMed]

82. Vital, S.A.; Senchenkova, E.Y.; Ansari, J.; Gavins, F.N.E. Targeting AnxA1/Formyl Peptide Receptor 2 Pathway Affords Protection against Pathological Thrombo-Inflammation. Cells 2020, 9, 2473. [CrossRef] [PubMed]

83. Drieu, A.; Levard, D.; Vivien, D.; Rubio, M. Anti-inflammatory treatments for stroke: From bench to bedside. Ther. Adv. Neurol. Disord. 2018, 11, 1756286418789854. [CrossRef] [PubMed]

84. Prestigiacomo, C.J.; Kim, S.C.; Connolly, E.S., Jr.; Liao, H.; Yan, S.F.; Pinsky, D.J. CD18-mediated neutrophil recruitment contributes to the pathogenesis of reperfused but not nonreperfused stroke. Stroke 1999, 30, 1110-1117. [CrossRef] [PubMed]

85. Suzuki, H.; Hayashi, T.; Tojo, S.J.; Kitagawa, H.; Kimura, K.; Mizugaki, M.; Itoyama, Y.; Abe, K. Anti-P-selectin antibody attenuates rat brain ischemic injury. Neurosci. Lett. 1999, 265, 163-166. [CrossRef]

86. Enlimomab Acute Stroke Trial, I. Use of anti-ICAM-1 therapy in ischemic stroke: Results of the Enlimomab Acute Stroke Trial. Neurology 2001, 57, 1428-1434. [CrossRef]

87. Ansari, J. Targeting Peptidyl Arginine Deiminase 4 and NADPH Oxidase Pathway Regulates Neutrophil Dependent ThromboInflammation. Br. J. Pharmacol. 2020, 178, 409-410.

88. Carpenter, A.C.; Alexander, J.S. Endothelial PKC delta activation attenuates neutrophil transendothelial migration. Inflamm. Res. 2008, 57, 216-229. [CrossRef]

89. Yoo, J.; Nichols, A.; Song, J.C.; Mammen, J.; Calvo, I.; Worrell, R.T.; Cuppoletti, J.; Matlin, K.; Matthews, J.B. Bryostatin-1 attenuates TNF-induced epithelial barrier dysfunction: Role of novel PKC isozymes. Am. J. Physiol. Gastrointest. Liver Physiol. 2003, 284, G703-G712. [CrossRef]

90. Tan, Z.; Turner, R.C.; Leon, R.L.; Li, X.; Hongpaisan, J.; Zheng, W.; Logsdon, A.F.; Naser, Z.J.; Alkon, D.L.; Rosen, C.L.; et al. Bryostatin improves survival and reduces ischemic brain injury in aged rats after acute ischemic stroke. Stroke 2013, 44, 3490-3497. [CrossRef]

91. Hankey, G.J. The benefits of aspirin in early secondary stroke prevention. Lancet 2016, 388, 312-314. [CrossRef]

92. Awtry, E.H.; Loscalzo, J. Aspirin. Circulation 2000, 101, 1206-1218. [CrossRef]

93. Rothwell, P.M.; Giles, M.F.; Chandratheva, A.; Marquardt, L.; Geraghty, O.; Redgrave, J.N.; Lovelock, C.E.; Binney, L.E.; Bull, L.M.; Cuthbertson, F.C.; et al. Effect of urgent treatment of transient ischaemic attack and minor stroke on early recurrent stroke (EXPRESS study): A prospective population-based sequential comparison. Lancet 2007, 370, 1432-1442. [CrossRef]

94. Meadows, T.A.; Bhatt, D.L. Clinical aspects of platelet inhibitors and thrombus formation. Circ. Res. 2007, 100, 1261-1275. [CrossRef]

95. Hackam, D.G.; Spence, J.D. Antiplatelet Therapy in Ischemic Stroke and Transient Ischemic Attack. Stroke 2019, 50, 773-778. [CrossRef]

96. Johnston, S.C.; Easton, J.D.; Farrant, M.; Barsan, W.; Conwit, R.A.; Elm, J.J.; Kim, A.S.; Lindblad, A.S.; Palesch, Y.Y. Clopidogrel and Aspirin in Acute Ischemic Stroke and High-Risk TIA. N. Eng. J. Med. 2018, 379, 215-225. [CrossRef]

97. Wang, Y.; Wang, Y.; Zhao, X.; Liu, L.; Wang, D.; Wang, C.; Wang, C.; Li, H.; Meng, X.; Cui, L.; et al. Clopidogrel with Aspirin in Acute Minor Stroke or Transient Ischemic Attack. N. Engl. J. Med. 2013, 369, 11-19. [CrossRef] [PubMed]

98. Johnston, S.C.; Amarenco, P.; Denison, H.; Evans, S.R.; Himmelmann, A.; James, S.; Knutsson, M.; Ladenvall, P.; Molina, C.A.; Wang, Y. Ticagrelor and Aspirin or Aspirin Alone in Acute Ischemic Stroke or TIA. N. Engl. J. Med. 2020, 383, 207-217. [CrossRef] [PubMed]

99. Johnston, S.C.; Amarenco, P.; Albers, G.W.; Denison, H.; Easton, J.D.; Evans, S.R.; Held, P.; Jonasson, J.; Minematsu, K.; Molina, C.A.; et al. Ticagrelor versus Aspirin in Acute Stroke or Transient Ischemic Attack. N. Engl. J. Med. 2016, 375, 35-43. [CrossRef]

100. Wang, Y.; Meng, X.; Wang, A.; Xie, X.; Pan, Y.; Johnston, S.C.; Li, H.; Bath, P.M.; Dong, Q.; Xu, A.; et al. Ticagrelor versus Clopidogrel in CYP2C19 Loss-of-Function Carriers with Stroke or TIA. N. Engl. J. Med. 2021. [CrossRef] [PubMed]

101. Diener, H.C.; Cunha, L.; Forbes, C.; Sivenius, J.; Smets, P.; Lowenthal, A. European Stroke Prevention Study. 2. Dipyridamole and acetylsalicylic acid in the secondary prevention of stroke. J. Neurol. Sci. 1996, 143, 1-13. [CrossRef]

102. Wieberdink, R.G.; van Schie, M.C.; Koudstaal, P.J.; Hofman, A.; Witteman, J.C.; de Maat, M.P.; Leebeek, F.W.; Breteler, M.M. High von Willebrand factor levels increase the risk of stroke: The Rotterdam study. Stroke 2010, 41, 2151-2156. [CrossRef] [PubMed]

103. Bongers, T.N.; de Maat, M.P.; van Goor, M.L.; Bhagwanbali, V.; van Vliet, H.H.; Gómez García, E.B.; Dippel, D.W.; Leebeek, F.W. High von Willebrand factor levels increase the risk of first ischemic stroke: Influence of ADAMTS13, inflammation, and genetic variability. Stroke 2006, 37, 2672-2677. [CrossRef] [PubMed]

104. Buchtele, N.; Schwameis, M.; Gilbert, J.C.; Schörgenhofer, C.; Jilma, B. Targeting von Willebrand Factor in Ischaemic Stroke: Focus on Clinical Evidence. Thromb. Haemost. 2018, 118, 959-978. [CrossRef] [PubMed] 